\title{
Urbanization in China: Through the City Construction in Qingming Scroll and the Proposition of New-Type Urbanization
}

\author{
Yuxi YI ${ }^{1}$ \\ ${ }^{1}$ Diplôme du Collège Universitaire de Sciences Po - Politique et Gouvernement - 3ème Année, Sciences Po de Paris, Paris, \\ France \\ Correspondence: Yuxi YI, Diplôme du Collège Universitaire de Sciences Po - Politique et Gouvernement - 3ème Année, \\ Sciences Po de Paris, Paris, France.
}

Received: June 29, 2021

doi:10.11114/ijsss.v9i5.5330
Accepted: August 18, $2021 \quad$ Available online: August 19, 2021

URL: https://doi.org/10.11114/ijsss.v9i5.5330

\begin{abstract}
In the 2019 Government Work Report of The State Councill, Prime Minister of the People's Republic of China, Li Keqiang, stressed the need to "promote coordinated regional development and improve the quality of new-type urbanization." The Government Work Report of The State Council in May 2020 puts forward the basic principles of strengthening the new-type urbanization and improving the capacity of public service facilities ${ }^{2}$. (Xinhua News Agency [XNA], 2020). It is necessary to promote sustainable and livable urbanization. What should urbanization be like in the case of the new type as a crucial task of construction? How should it deepen the reform of the household registration system and promote economic development beyond the population balance of cities? Based on city clusters, how should urbanization further be promoted and comprehensively driven the Chinese economy after the epidemic? Will the "street stall economy" and "small shop economy" jointly proposed by the Central Civilization Office and Prime Minister in 2020 be a new opportunity? By reviewing Urbanization in China (2019) written by Houkai Wei, this paper believes that Qingming Scroll, as an observable example of the economic prosperity of the Northern Song Dynasty, can be a breakthrough in the analysis of the new-type urbanization. Taking the urbanization of the Northern Song Dynasty shown in Qingming Scroll as a base, this paper will further give a new answer on how to further develop and improve the new urbanization. Based on the analysis of the national urbanization of Bianjing in the Northern Song Dynasty shown and the process given by Urbanization in China, this paper further speculates and constructs the possibility of development. Therefore, according to the characteristics of cities and the nature of urban development in the Northern Song Dynasty, this paper tries to analyze the structure of urbanization in New China and discusses feasible new ways of the urban economy.
\end{abstract}

Keywords: new urbanization, Qingming Scroll, Hukou system, Street-Stall economy

\section{Introduction}

\subsection{Introduce the Background}

With the development of social productive forces, the progress of science and technology, and the adjustment of industrial structure in a country, society is gradually developing. The country grows from the traditional rural communities based on agriculture to the modern city community on the industry, service industry, and other non-agricultural industries. This process is called urbanization. Historically, it was inextricably linked with the Industrial Revolution. During the industrial revolution in Britain in the middle of the 18th century, many new industrial centers formed. And the original economically backward areas were replaced by the cotton spinning industry and industrial centers. In the United States at the beginning of the 19th century, the Industrial Revolution took the lead in the cotton textile industry. New mills were built in Massachusetts, Connecticut, and elsewhere. Urbanization was not only the result of the building of factories and the development of textiles. Both economic development and population boom are regarded as the basic characteristics of urbanization. Between 1841 and 1846, the population of Paris increased by 120,000. It was at a time when the whole world was progressing but China, which had delayed the completion of the

\footnotetext{
${ }^{1} \mathrm{Li}$, Keqiang. (2019). Report on the Work of the Government of the State Council.

2 Xinhua News Agency. (2020). Report on the Work of the Government for 2020.
} 
industrial revolution, was still in a social state of agriculture. After the founding of the People's Republic of China in 1949, the situation gradually improved. After the reform and opening up, China lifted the original control of population flow, and many migrant workers moved to cities, speeding up urbanization.

\subsection{Explore the Problem and Its Importance}

Urbanization is one of the main topics for this paper. The word in Chinese is known as metropolitan-ization, city-ization, and urban-ization. Taking the current general concept and the National New Urbanization Rules ${ }^{3}$ as the benchmark, all the urbanization mentioned in this paper has the same meaning. (National Development and Reform Commission [NDRC], 2016). They are all referred to as China's basic plan to promote the orderly developing farmer's citizenship of the quasi-one agricultural population and encourage the rural population to settle down. This paper will take the already developed urbanization foundation as the background. And it will rethink the new type of China's urbanization, which should be the direction of the problem. It is a question worth discussing. After the policy guidelines of "Developing and Improving the Quality of New-Type Urbanization" have been issued in the 2019 Government Work Report of The State Council, the development prospect of new-type urbanization and its model is worthy of attention. It is crucial to China's future economic development. Therefore, it is vital to explore the future of China's urbanization.

\subsection{Describe Relevant Scholarship}

Houkai Wei's Urbanization in China is the most important research material of this paper. It is a book tracing the history of China's Urbanization. It discusses the social change in China, as well as the problems and challenges it is facing. Houkai Wei (2019) suggested that China's construction method is not merely about building more cities but also building better cities. The word "good" here is similar to the State Council government report $(2020)^{4}$ on "vigorously improving the capacity of public services and facilities," which also says cities should be better for both people and the environment. In several chapters of the book, Houkai Wei indicates that the impact of China's existing multiple aspects of industrialization, ecological modernization, and informatization on new urbanization strategies and policies. This has much in common with the concept that "China's urbanization level lags behind China's domestic economic development level ${ }^{5}$." (Jian and Huang, 2010). However, this paper holds that China's urbanization has come to a saturated state. Thus, it has to face a new transformation. According to the changing society and the economy battered by the epidemic, China's urbanization needs to be inspired by more innovative ideas.

\subsection{Research Design}

Firstly, this paper will discuss the macroscopic concept of urbanization. The process of urbanization is constantly updating and changing. Urbanization has occurred at all stages of Chinese history. But urbanization in the past only existed in countries that relied on agriculture. Today, China has shifted from "urbanization with Chinese characteristics" to "new type urbanization." And Chinese urbanization has become an organic whole combining Chinese characteristics and new-type urbanization. It is a new development path. It takes into account China's fundamental national conditions and elements at different stages of development. At the same time, we insistence pursue efficient and green progress, low carbon emissions, and integrated urban and rural development. It is also a cultural inheritance highly coordinated with industrialization and agricultural modernization. The new type of urbanization to be developed is based on the basic principle of putting people first. Only by putting people first can we have the opportunity to meet the various demands of the new type of urbanization.

Secondly, since the macro analysis of urbanization cannot fully adapt to the development process of urbanization in China, the most appropriate way is to detail urbanization. Cities appear because of the development of a country and the increase of its population. Because there are more and more people, you have clusters. Clusters lead to more employment opportunities, industrial development, and other areas of development. On this basis, urban population density planning, spatial planning, and urban population-scale statistics become the essential issues that must be solved in the construction of urbanization with Chinese characteristics and the combination of urbanization with the new green concept of sustainable development with Chinese characteristics. The key to solving this problem is to reform the household registration system.

Beyond that, it is the economy that matters most to the plan. Therefore, in the last part, this paper will mainly analyze China's urban economy. Since the reform and opening up, China has created a series of economic miracles. China's economic wonder has manifested itself in three main ways. First, the Chinese economy has maintained rapid growth for

\footnotetext{
${ }^{3}$ National Development and Reform Commission. (2016). National New Urbanization Rules (2014-2020).

${ }^{4} \mathrm{Li}$, Keqiang. (2020). Report on the Work of the Government of the State Council.

5 Jian, Xinhua and Huang, Kun. (2010). Empirical Analysis and Prospect Forecast of China's Urbanization Level and Speed.
} 
more than 30 years. Hu Jintao, former General Secretary of the CPC Central Committee and President of the People's Republic of China, said at the Third Plenary Session of the Eleventh CPC Central Committee (2008) that China's GDP had grown at an average annual rate of 9.8 percent from 1978 to 2007. Second, the comprehensive poverty alleviation announced by President Xi Jinping (2021) shows that about 750 million Chinese people have been lifted out of poverty in the past 35 years. That is why China is working hard to achieve the United Nations Sustainable Development Goals. Third, China is urbanizing at an unprecedented rate. For choosing the road of new-type urbanization, China's new-type urban economy needs innovation and breakthrough. So we will study the golden age of history. Through the Northern Song Dynasty economic pattern of the study, the further development of today's economy. The paper also discusses the possible new ways of urban economy: street stall and shop economy.

\section{Method}

\subsection{Identify Review Method}

In terms of research methods, this paper as an academic review paper is different from other scientific papers. This paper can be said to be a review of the existing literature, that is, a review and analysis of the literature. After collecting a large number of relevant data in line with the topic of this paper, a cutting-edge academic suggestion is made through reading, analysis, induction, and sorting out. This paper is devoted to the discovery of a new level, new trends, and new technologies through the research of the current situation in this field and the extensive reading of a series of literature that has been consulted. The main analysis of this paper is based on Houkai Wei's Urbanization in China ${ }^{6}$. (Wei, 2019). In the process of the macroscopic urbanization of new China, this paper finds three important aspects, namely, the macroscopic concept of new urbanization, the data analysis of urban population and space, and the promotion and development of the urban economy. (Wei, 2019). And along these three aspects to give a more detailed analysis and refinement, from multiple perspectives to improve the history and policy of China's urbanization, and better understand why urbanization is given a new definition.

\subsection{Other Characteristics}

Therefore, this method of literature research, through the process of a literature survey to obtain data, comprehensively and correctly meets the research purpose of innovative and critical thinking on urbanization. In addition, on the basis of this literature research method, this paper also uses the concept of interdisciplinary research, namely the so-called cross research method, to synthesize the theories, methods, and achievements of other disciplines as a whole. Here, this approach focuses on art and historical research methods. The reason is that Qingming Scroll is used as a primary source in this paper to show the urbanization cases in the special period of the Northern Song Dynasty. By comparing the details in Qingming Scroll's paintings, the author attempts to reproduce the characteristics of the city in the Northern Song Dynasty and the living characteristics of the people in the city. At the same time, this paper also supplemented other ancient Chinese literature that depicted the urbanization scenes in the Northern Song Dynasty. Through the supplementary explanation of these literary works, this paper can better describe the process of urbanization in the Northern Song Dynasty, at the same time show the city scenes and characteristics of that prosperous years, and compare with the urbanization with Chinese characteristics today.

\section{Results}

\subsection{Analysis the Policy and Main Meaning of Urbanization in New China}

China ranked number one for the concern of population in the world. It is also so-called the third-largest land area in the world. Therefore, the big difference between urban and rural areas and the limited resources have become the reasons for the great difference between China's urbanization and other urbanization. "Taking a new road of urbanization with Chinese characteristics is an important part of building a country with socialist characteristics, as well as the foundation of building a harmonious, prosperous society and rejuvenating the nation." (Ministry of Foreign Affairs of the People's Republic of China [MFAPRC], 2002). According to Urbanization in China written by Houkai Wei (2019), the fundamental purpose of urbanization is to reconcile the existing set of problems and stop the country from remaining an agricultural society. As well as seeking breakthroughs, it should ensure sustainable prosperity and national renewal. Thus, China (PRC) has made the country what it is today in just 71 years. China became an economic power. She has taken a special road of urbanization with Chinese characteristics. In this paragraph, the paper will explore how this approach to characteristic socialism echoes the history of urban construction in China over the past five thousand years

\footnotetext{
6 Wei, Houkai. (2019). Strategic Thinking About Urbanization in China: The Path to Harmony and Prosperity. Urbanization in China.

${ }^{7}$ Ministry of foreign affairs of the People's Republic of China. (2002). Full text of Jiang Zemin's Report at 16th Party Congress on Nov. 8, 2002.
} 
(3.1.1). This paper will also analyze China's urbanization and delve into how it combines with the cultural, agricultural, and industrial heritages in an existing urban context (3.1.2).

\subsubsection{The Branded 5000-year Chinese Culture and History on the New Method of Urbanization}

Nowadays, Chinese scholars have managed in-depth researches on the road of Urbanization in China, especially "urbanization with Chinese characteristics" and "new-type urbanization." Both are based on socialism with Chinese characteristics. This is a kind of integrated development view that includes road, theory, system, and culture. Its theoretical system is the latest theoretical achievement of the Communist Party of China which is in combining Marxism with Chinese reality. Socialism with Chinese characteristics is a product of the combination of the basic principles of scientific socialism with China's actual conditions. It has distinct characteristics of the time and China.

In the book Urbanization in China, the author reviews the literature from the past. He then gives an in-depth explanation of the meaning of the existing new socialist urbanization path in China. Nowadays, there is no consensus among scholars on what "urbanization with Chinese characteristics" means. Zhan (2003) believes that it should be as a whole of urbanization, industrialization, and modernization. Urbanization takes a variety of forms, with towns large and small developing in a coordinated manner and promoted by top-down measures guided by the government. Xiao (2008) believes that the urbanization path with Chinese characteristics refers to the goal of coordinating urban and rural development and letting big cities help small cities, taking into account the main characteristics of China's large population and insufficient arable land. It is conducive to the reasonable resources allocation, urban environmental progress, and adaptation to regional development diversification, to promote the formation of a resource-saving, eco-friendly, economically efficient, and socially harmonious urban development pattern.

Although scholars have some analyses on urbanization under socialism with Chinese characteristics, they share a common thread of interpretation. To sum up, the road of urbanization needs to meet five requirements: First, China's per capita inequality of resources, and then realize the full use of land, while improving the efficiency of the progress of urbanization. Second, to exist and proceed in a regional basis manner that adequately reflects the physical conditions, economic and social development, and differences in resource allocation in the relevant regions. Third, holding at a stable and reasonable rate. It also should be subject to the constraints of employment and economic growth. Fourth, for enabling all stakeholders to play their appropriate roles. Fifth, promoted urbanization per the core socialist principle of "eliminating serious inequality and pursuing common prosperity."

The theory of urbanization with the special Chinese concern is satisfied the above five conditions. However, the new-type urbanization is different. The concept of "new-type urbanization" is not entirely new. Since 2008 , the new urbanization road with Chinese characteristics has entered the public view. Wu Zequn's paper "the practical significance of the new urbanization road" is the embodiment of this time node ${ }^{8}$. (Wu, 2008). Also, at the Central Economic Work Conference (2013), Xi announced the start of "an efficient, smart, green and low-carbon new urbanization path. ${ }^{9}$ The new-type urbanization is a process of both urban and rural development that is mainly based on people and promotes the new industrialization of modernization. This new type of urbanization has four characteristics. First of all, industrialization, urbanization, industrial application, and agricultural modernization should interact with each other and coordinate comprehensively. In other words, based on roads with Chinese characteristics, informationized urbanization transition behavior has been added. The four transformations are then coordinated with each other. Under this principle, industry and urban integration development, thus the rural civilization can be conserved. Second, the coordination of population, resources especially in economic concerns, and factors mostly in environmental aspects. This coordination promotes an efficient urbanization rate and green low-carbon urbanization development. Thirdly, the coordination of urban planning and design with a geographical financial and manufacturing development. The combination of the development of regional economy and industry, urban design, and a regional economy based on previous Chinese characteristics promotes the formation of China's urbanization. Fourth, China should emphasize the development of comprehensive, inclusive, and harmonious people. It's a return to a people-centered foundation.

Both the socialist characteristic urbanization and the green and efficient urbanization are new systems of urban formation in Chinese history. The emergence of Chinese cities can be traced back to the Longshan Era in 2800 BC. From the Xia Dynasty to the late Tang Dynasty and the Five Dynasties, the urban development in China had formed an "administrative city" with Confucian thought as the rule and principle. Based on agriculture, the city was an administrative center of the dynasty and the state for about three thousand years from the Northern Song Dynasty to the present day. The essential function of the city is to serve the surrounding agriculture and countryside. During the

\footnotetext{
${ }^{8} \mathrm{Wu}$, Zequn. (2008). The Practical Significance of the New Urbanization Road.

${ }^{9}$ Xinhua News Agency. (2013). Xi Jinping and Li Keqiang made important speeches at the Central Economic Work Conference.
} 
Northern Song Dynasty, great changes took place in Chinese civilization and urban development. The capital of the Northern Song Dynasty; Banjing shows the big development history of China's urban industry and commerce. Bianjing is the city recorded in the royal painting Qingming Scroll. This has also become a witness to the development of Chinese cities and a basis for investigation. Therefore, this paper will make use of the details in the works to further supplement the formation of China's urbanization and the development of new urbanization. The Northern Song Dynasty began this urbanization which lasted for thousands of years and formed the accumulation. Even though China was an agricultural country as for the Song Dynasty, the functions of cities were people-oriented and ecologically oriented. So, that's one of the reasons: borrowed. It fully proves the connectivity with the new urbanization.

Based on the five thousand years of history and culture, the new green cities on the road of characteristic urbanization are returning to the people-oriented thoughts of the Northern Song Dynasty. This process of regression and re-creation gradually develops into an organic whole. Therefore, under the premise that China adheres to the new-type urbanization road with the Chinese characteristics, which takes the quality of urbanization as the core. China's urbanization is constantly absorbing ancient nutrition.

\subsubsection{The Continuation of Cultural, Agricultural, and Industrial Heritage by Urbanization}

The construction of a city is inseparable from the relationship between culture, agriculture, and industry. According to Kao Gong Ji, "Jiangren Yingguo, Fangjiu Li, Pangsan Men. Guozhong Jiujing Jiuwei, Jingtu Jiugu. Zuozu Youshe, Mianchao Houshi. ${ }^{10 "}$ (Wen, 1993). This is a mode of thinking that pays more attention to administration than to the market. When architects built the capital city, the city plan was square, with sides nine li long. There are eighteen streets in the city, nine verticals and nine horizontals. Streets are so wide that nine carriages can ride at a time. In front of the palace is the place where the courtiers worship, and in the back is the market. The marketplace and the place of worship in front of the palace were two squares with sides one hundred paces long. The market here does not refer to the whole economy, but specifically to the non-agricultural economy. At that time, the non-agricultural economy was not valued. But the economy itself still has a profound effect on urbanization. "Kao Gong Ji" is derived from the Confucian classic "Zhou Li." It lists the written rules of traditional Chinese cities, including the rules of urban planning in the past dynasties since the Zhou Dynasty. ${ }^{11}$ This is to say that in the traditional Chinese cultural system, the purpose of urbanization is to promote the government and maintain the worldview and management style of the times. The planning for urbanization was divided into three concepts: central governance, order, and class relations. This builds a logical relationship. It is a prescriptive link between the various contents existing in a city. Confucianism, Buddhism, and Taoism added on the urban construction thought since the Zhou Dynasty, and then combined with communism, we have today's urbanization.

The new urbanization must promote the integration of informatization and industrialization. Moreover, it should strengthen the interaction between industrialization and urbanization. And then promote the coordinated improvement between urbanization and agricultural modernization. In other words, the process is underpinned by industrialization. The premise is cities as carriers, information as an aid, and agricultural modernization as a foundation. Urbanization must be closely integrated with these three concepts. Then, together, we will form a new pattern of coordinated development. In addition, the industrial structure of the city should be optimized employing high and new technologies such as electronics and information. So the level of industrialization has risen accordingly ${ }^{12}$. (Wei, 2019). Under the benign interaction of industrialization and urbanization, agricultural modernization has also been inevitably promoted.

Urbanization and agricultural modernization go hand in hand. By helping each other, they can promote urban and rural prosperity. They can also solve the persistent problems of urban and rural diseases.

The new-type urbanization must reflect China's history and culture. The construction of urbanization reflects the historical features, cultural deposits, local characteristics, and national characteristics. The urbanization model of New China is trying to highlight local and national characteristics and integrate local arts and cultural features into the development of cities and towns ${ }^{13}$. (Wei, 2019). From the point of view of urbanization, it should mainly emphasize the regional natural, historical and cultural factors. It should also promote diversity and give character to different regions.

\footnotetext{
${ }^{10}$ Wen, Renjun. (1993). Translation and Annotation of Kao Gong Ji. Shanghai Ancient Books Publishing House.

${ }^{11}$ When the architects built the capital, the city was square with nine Li sides. Each side had three gates (two side gates). There are nine north-south roads and nine East-West roads in the city.

${ }^{12}$ Wei, Houkai. (2019). Strategic Thinking About Urbanization in China: The Path to Harmony and Prosperity. Urbanization in China. Chapter 8, 199-201.

${ }^{13}$ Wei, Houkai. (2019). Strategic Thinking About Urbanization in China: The Path to Harmony and Prosperity. Urbanization in China. Chapter 8, 203..
} 
As a part of the construction of new socialist countryside, it should also focus on building a different, sustainable, and aesthetically pleasing countryside. This is one of the main concerns for building up the system of new-type urbanization. The construction of new rural areas will improve farmers' lives and then strengthen rural facilities and service networks. China with a large number of population concerns has always been a country dominated by agriculture. Even after industrialization, agriculture is still an important part of the People's Republic of China. Therefore, one of the foundations of urban construction is to promote the new development and construction of rural areas. In addition to improving the convenience network of natural villages, ethnic villages with historical, artistic, and scientific values should also be given special protection and reservation. In short, the new urbanization under the leadership of China's socialist core values is guided by the new China's scientific outlook on development. At the same time, it also integrates the concept of sustainable development into its construction basis.

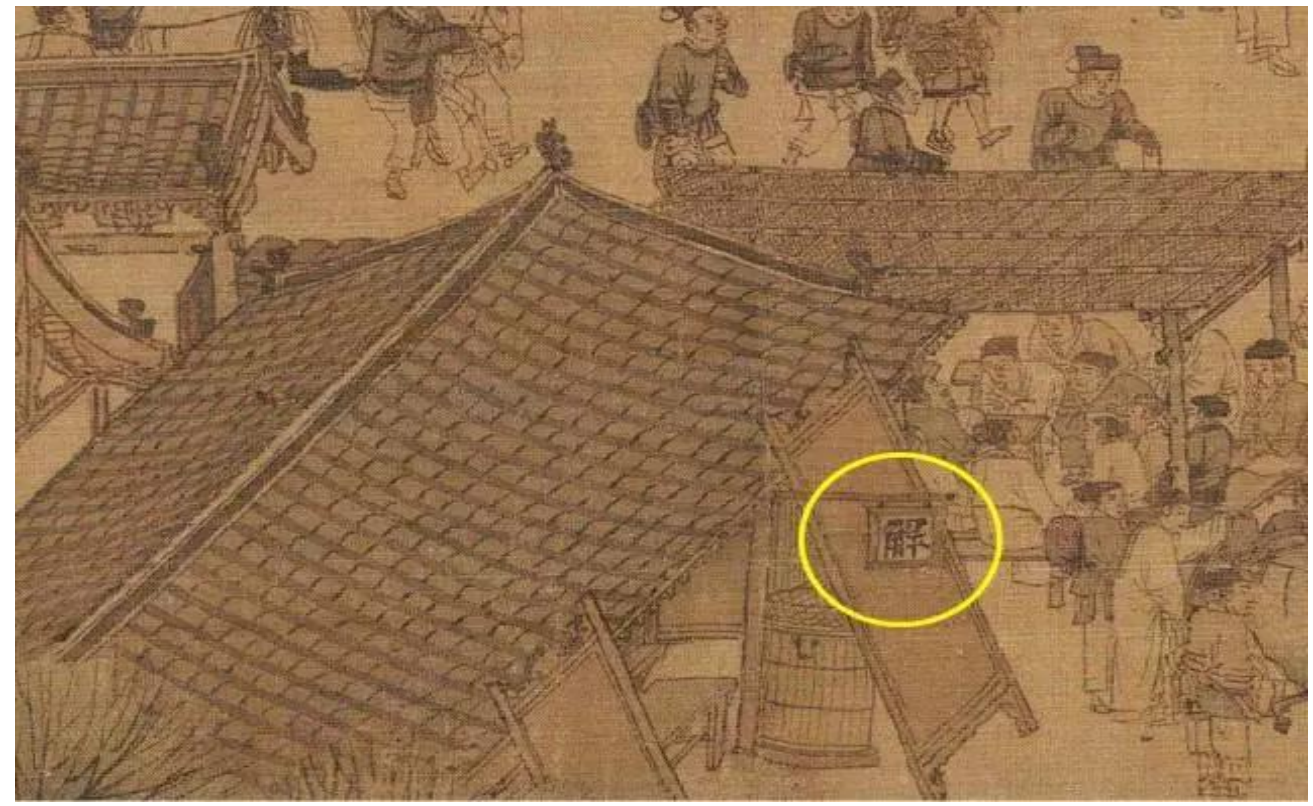

Figure 1. Recreation places on the Qingming Scroll

Source: Qingming Scroll (Anonymous, 2020).

Culture and cultural heritage can be thought of as being based on people as a group. Just as in the Northern Song Dynasty, there was a civilization product called civic culture, which mainly referred to the city's comprehensive entertainment venues called "Wazi ${ }^{14}$." (Song, 2011). According to the "Qingming Scroll," there are some "Wazi" in the Kaifeng area of the Song Dynasty. This is the first urban space or we called public space in history formed by a large number of citizens and vendors. This space is a large integrated entertainment area. Around this area, there are many places for story-telling, buying books, calligraphy, painting, paper-cutting, or divination. Figure 1 is a scene from Qingming Scroll. In front of a store with the word "Jie (Solution)", a speaker was surrounded by a crowd of people. These are the new products of civilization, and the source of their products is man himself.

Thus, today's new urbanization will also focus on a people-centered approach in demonstrating the so-called links between culture, cities, agriculture, and information. Returning to the idea of developing cities in the Northern Song Dynasty, we should think about the content of folk culture and folk thoughts from the perspective of human beings.

\subsection{Data Analysis of Planning and Supplement of Urban Space and Population in China}

The macro-situation and theoretical development orientation of China's new-type urbanization have been expounded in detail in the previous part. From the perspective of urban planning, this part will elaborate on the existing urbanization phenomenon and the urban development in China over the years. Urban planning management is closely related to the number, density and registration system of urban population. In addition to population, there is also the spatial planning and management of Chinese cities. In emergencies, for example, urban water, electricity, gas, transport, communications, and logistics are all related to urban spatial planning and management. The outbreak of severe acute respiratory syndrome (SARS) in 2002-2003, the snow and ice disaster in southern China in early 2008, the rainstorm in

${ }^{14}$ Song, Li. (2011). On the Management of Bianjing Commercial Market in Northern Song Dynasty. 
Beijing in 2012, and the epidemic in Wuhan in 2020 have given a wake-up call to China's urban space management. The new urbanization should learn from it and create it. According to Houkai Wei's Urbanization in China (2019), this paper believes that urbanization in China should be improved during the process of new-type urbanization to adapt to future urbanization. Its efforts should focus on changing the philosophy (3.2.1), structure (3.2.2), priorities, and methods of urban management (3.2.3).

3.2.1 Spatial Planning Constraints Brought by Population Density

Table 1. Cities in China by region, $2013^{15}$

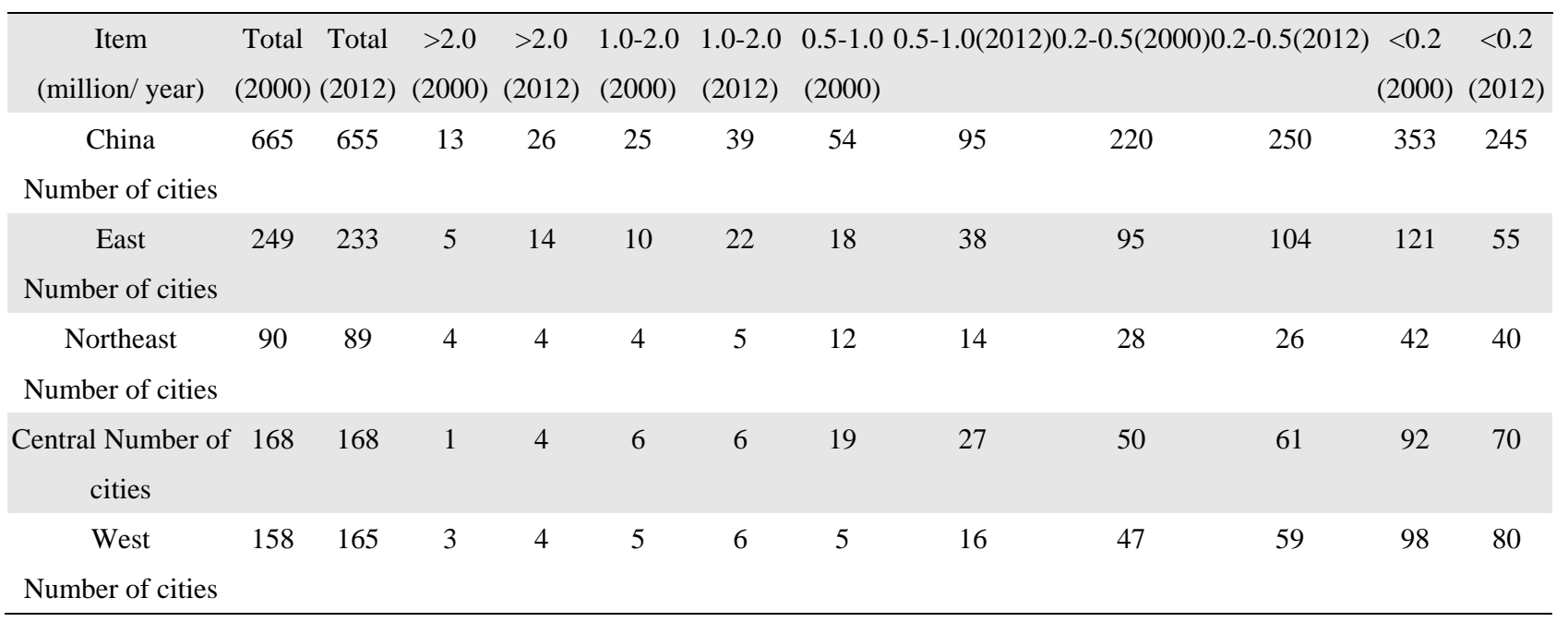

Table 2. Population percentage in China by region, $2013^{16}$ (Urban population sizes are non-agricultural.)

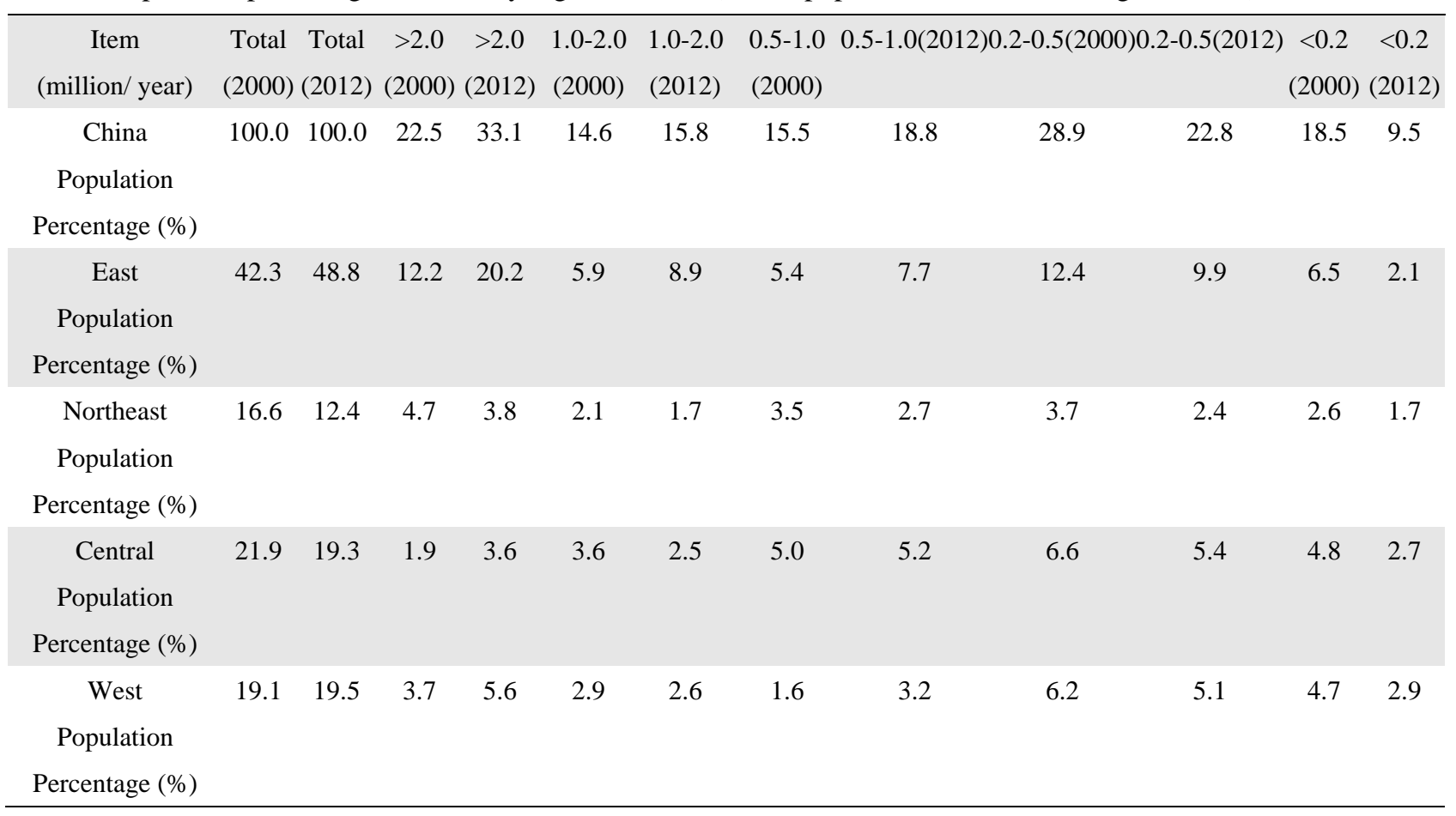

${ }^{15}$ China Population and Employment Statistics Yearbook. (2013).

${ }^{16}$ China Population and Employment Statistics Yearbook. (2013). 
The high density of cities and urban residents in China's coastal areas is mainly reflected in three aspects: first, there is a sharp contrast between the cities in the southeast of the Aihui-Tengchong line and those in the Northwest. Aihui-Tengchong line is a geographical line used to divide China, which divides China into southeast and northwest regions ${ }^{17}$. (Wei, 2019). It can be seen from table 1 and table 2 that the Southeast region accounts for $45 \%$ of China's land area, but $89.65 \%$ of China's cities and $94.3 \%$ of China's total urban population. Second, the number of cities in China's four major regions has dropped sharply from east to west. According to the data in 2012, although the land area in East China only accounts for $10 \%$ of the country, there are 233 cities, accounting for $48.8 \%$ of the country's non-agricultural population. In contrast, the western region accounts for $72 \%$ of China's land area. Besides, there are merely 165 cities and less than $20 \%$ of the non-agricultural population. From the spatial distribution of city size, East China constitutes $46.3 \%$ of the larger cities in China, especially cities with a population of one million ${ }^{18}$. (Wei, 2019).

However, the big cities in Western China are not as big as those in eastern China. It is very difficult to find the area that can be compared with the big cities in East China. There are 26 big cities in the whole western region. The inequality of China's urbanization is also reflected in the differences in the number and density of cities in different provinces. In terms of the number of cities, there were 657 cities in 2011, and only 10 provinces with more than 30 cities, including Shandong, Henan, Guangdong, Jiangsu, Hubei, Zhejiang, Hebei, Liaoning, Sichuan, and Heilongjiang. These provinces together account for $55 \%$ of the total number of cities in the country. Among them, Shandong and Guangdong have the largest number of cities: 48 in Shandong and 44 in Guangdong. What's more, there are fewer than 10 cities in Hainan Province, Ningxia Autonomous Region, Qinghai Province, and Tibet Autonomous Region. Therefore, from the perspective of urban density, China has an average of 0.078 cities per 1000 square kilometers ${ }^{19}$. (Wei, 2019). But these cities are concentrated in some areas, and in some areas, there are few cities. In general, most of China's densely populated urban provinces are located in the economically developed and naturally developed eastern part of the country (here referred to as the eastern part of the country). At the same time, the density of the urban population is higher in places with higher urban density. Provinces with low urban density are mostly concentrated in the large, poor natural conditions and underdeveloped western regions. In space, the number of cities decreases from east to middle to west, as shown in Figure 2. Figure 2 shows the population of urban areas in China. The red spherical icon on the green map shows the population density of a city. The smaller the ball icon, the smaller the population density of the region, while the larger the icon for autumn clothing, the greater the population density of the region. In particular, this chart reflects the relationship between cities in eastern and western China and population density.

Since the reform and opening up, China is still following the traditional road of urbanization and facing a series of outstanding problems. The first problem is that "land urbanization" takes precedence over "population urbanization." Population urbanization refers to the dynamic process in which the rural population is constantly transformed and concentrated into cities and the proportion of the urban population in the total population is gradually increased. Population urbanization is aimed at improving the quality of life of its inhabitants. In its current state, the Hukou system has brought many new restrictions and improvements to urbanization. A large number of migrant workers mainly causes the incompleteness of urbanization. Because migrant workers are different from ordinary urban and rural residents. They are people outside the urban system, sandwiched between urban and rural areas. And no matter what their status is, they still have the living habits and characteristics of farmers ${ }^{20}$. (Wei, 2019). Therefore, this shows that the urbanization rate of Hukou is still very low ${ }^{21}$. In 2013, there were 269 million migrant workers in China, 166 million of 269 million are migrant workers ${ }^{22}$. (Wei, 2019). Most of these non-local migrant workers need to work and live in the city. Although they are regarded as urban residents, they are still unable to meet the living needs of urban residents in many other

${ }^{17}$ Wei, Houkai. (2019). Strategic Thinking About Urbanization in China: The Path to Harmony and Prosperity. Urbanization in China. Chapter 5, 101-102.

${ }^{18}$ Wei, Houkai. (2019). Strategic Thinking About Urbanization in China: The Path to Harmony and Prosperity. Urbanization in China. Chapter 5, 102-103.

${ }^{19}$ Wei, Houkai. (2019). Strategic Thinking About Urbanization in China: The Path to Harmony and Prosperity. Urbanization in China. Chapter 4, 71-73 and 93-94.

${ }^{20}$ Wei, Houkai. (2019). Strategic Thinking About Urbanization in China: The Path to Harmony and Prosperity. Urbanization in China. Chapter 9, 209-213.

${ }^{21}$ Hukou here means the formation process of newly registered urban residents.

${ }^{22}$ Wei, Houkai. (2019). Strategic Thinking About Urbanization in China: The Path to Harmony and Prosperity. Urbanization in China. Chapter 4, 85-87. 
aspects, such as employment, wages and welfare, children's education, social security, affordable housing, and so on ${ }^{23}$. (Wei, 2019). To sum up, in China's existing urban population, people with rural Hukou account for a large proportion, while permanent urban residents with non-local Hukou account for a large proportion. In 2011, the registered residence rate of permanent residents was only $35 \%$, which was 16.3 percentage points lower than that of all permanent residents $^{24}$. (Wei, 2019). This shows that the dual structure of urban and rural migration is much slower than that of urban China. This dual structure brings obstacles to population density and urban spatial structure. The first is to reduce the contribution of urbanization to domestic demand. In between the improvement of industrial structure and the improvement of workers' ability, it has also caused a lot of adverse effects. Secondly, compared with migrant workers, urban residents living rights and interests are extremely unequal. This seriously affects the harmony and stability of society. In addition, the difference in place of residence also makes it more difficult to manage people. Therefore, new urbanization needs to eradicate these three problems to meet its characteristics of efficiency. With the continuous development of electronics and technology, the digitalization of the Hukou system has become an important space for breakthroughs.

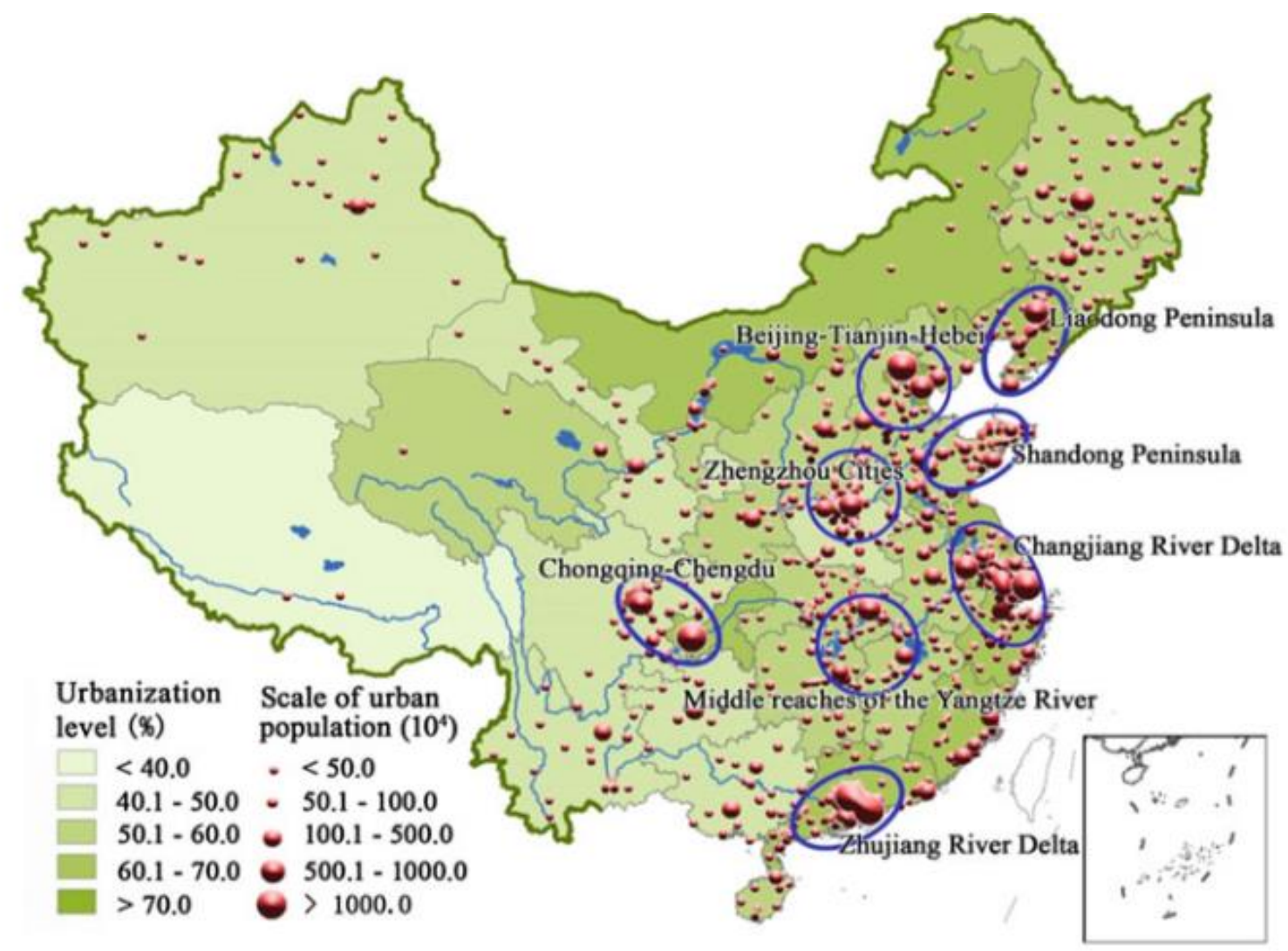

Figure 2. Spatial Pattern and Scale of Urban Population of China in 2015

Source: China Urban Construction Statistical Yearbook (2015)

23 Wei, Houkai. (2019). Strategic Thinking About Urbanization in China: The Path to Harmony and Prosperity. Urbanization in China. Chapter 1, 20-22.

${ }^{24}$ Wei, Houkai. (2019). Strategic Thinking About Urbanization in China: The Path to Harmony and Prosperity. Urbanization in China. Chapter 1, 209-210. 


\subsubsection{Optimization of Urban Spatial Structure}

The traditional cities of Chinese history have never been a single administrative or military unit. The concept of the city as an independent administrative body did not appear until the 20th century, which was a form borrowed from the West. However, due to the long-term urbanization from ancient times to now, China has always been in a specialized urbanization pattern. Chinese cities are mainly composed of municipal infrastructure, public utilities, traffic, and green management. Despite that, with the increasing complexity of the urban system, the relationship between urban subsystems becomes more complex. These subsystems can no longer run separately. Therefore, there are a series of problems in China's city management, including, but not limited to fragmentation, isolation, overlapping of functions, and inefficiency. (Song and Tang, 2007). Urban system development is a complicated process composed of many parts. It not only depends on the reasonable development of subsystems; but also depends on the coordination between them. It is necessary to strengthen urban administration, and then set up corresponding management departments and coordination mechanisms.

At present, the urban space in China is mainly determined by the types of urban functional zoning in the urbanization system. Most of them are divided into three major districts: commercial, industrial, and residential. The distribution and combination of these three regions form the internal spatial structure of the city. Among them, the commercial area covers a small area, which is generally in the form of dots or lines, appearing in the city center or on both sides of the traffic or at the intersection. The second is industrial areas, especially industrial cities. There is a certain proportion of cities in the exhibition of heavy industrial areas. Although much of the heavy industry has moved to the outskirts on the outer edge of the city, it is still largely concentrated and distributed in large areas. Finally, the residential area is the most extensive way of land use in the city, and it is also one of the main functions of the city. Most of them are in the shape of a piece, a group, and a point. Then, after the three major urban spatial functional zonings, other factors in the urban system have an impact on urban spatial planning. Taking the pictures in the Qingming Scroll as an example, there was a city management system called the "Xiangfang system"25 in the Northern Song Dynasty. (Zhou and Chen, 2007). This system was the regional office and several offices that later appeared in China. At that time the border divided the city into four compartments of forty-six square. There are altogether seventy-five rooms in the new city. That is to say, for urban space management, administrative management needs to divide certain urban spaces. And it also has an impact on the distribution of basic business districts and residential districts. According to the statistics in 1021, there are 32,555 households in Bianjing old city, with a total of four compartments of 46 mills. The new town has 65,200 households, with a total of six compartments of 75 mills $^{26}$. (Xue, 2017). Add in the royal family, nobles, palace maids, eunuchs, and a series of people in the palace, and the actual population should be around 1.11 million $^{27}$. (Wu, 1982). In terms of spatial distribution, the eastern part of the city has the largest number of Hukou due to the presence of royal palaces, shops, and households. From this perspective, today's urban space is also a reasonable layout according to functional areas. Meanwhile, the urban spatial structure inherits the governance model of the Northern Song Dynasty. The administrative department shall make a reasonable allocation between industrial land and residential land. The basic geographical environment needs to be properly planned, with a basic overview of pollution and urban ecology as well as inner regions.

The existing spatial structure problem is that China's super-large cities and megacities are approaching or exceeding the maximum carrying capacity of local resources and the environment. Facing the big cities with a population of more than 4 million, urban space management departments need to consider the limited carrying capacity of the environment and resources, reduce urban diseases and extremely negative impacts, and control the population size of large cities as soon as possible. Nowadays, China's cities are divided into several categories: Beijing, Shanghai, Tianjin, Chongqing, and Guangzhou are national cities; Shenzhen, Wuhan, Shenyang, Nanjing, Zhengzhou, Chengdu, Harbin, and other regions are central cities; the rest are ordinary cities. National cities and central cities are at the top of the whole system. They also play a very important leading role in China's urban agglomerations. As far as the current situation is concerned, the first thing to do is to maintain strict control over the size of the urban population. Only in this way, it can prevent and control urban diseases and excessive expansion of space. Take the current situation in Beijing as an example. In 2000, there were 13.82 million people in Beijing, with a total area of 16800 square kilometers. In 2020, the land area of

${ }^{25}$ Zhou Baozhu and Chen Zhen. (2007). The History of China: Song History. Chapter 3 "urban and rural divide and rule and the emergence of new registered residence system in urban and rural areas." Shanghai: People's Publishing House.

${ }^{26}$ Xue, Fengxuan. (2017). Qingming Scroll: memories of prosperity in the Northern Song Dynasty. Knowledge of literature and history 8,132 .

${ }^{27}$ Wu, Tao. (1982). The Construction and Layout of Bianjing in the Northern Song Dynasty (Vol 3). 
Beijing will be 16410.54 square kilometers, and the population will be 21.536 million. (National Bureau of Statistics [NBS], 2020). With the rapid increase of the population and the prevention and control of land expansion, population density will inevitably increase, and a series of other urban problems may exist, such as fire prevention, water use, street, and river management. Second, giving full play to the leading role and chain reaction of these cities in economic development. The key to solving this dilemma is to change the pattern of urban development and promote the comprehensive transformation and decentralization of urban functions. It requires a two-way, full-scale Hukou system to control population size. Besides, Industry standards will be controlled in the economic development of the city. Furthermore, the ideal function and development direction of the city make more detailed planning. Therefore, it is necessary to optimize the industrial structure of the city through policies. Then, affecting the planning of urban space. In addition, the urban transfer should be carried out under the limited carrying capacity of local environmental resources and public infrastructure. This transformation will promote the spatial structure optimization and regional integration of big cities, and improve their sustainability. In addition, the growth boundary of big cities must be determined according to the overall carrying capacity, livability, and sustainability, as well as the balance of work, life, and ecological space. Only by maintaining the basic elements of ecological development can the urban space be well planned.

\subsubsection{Unified Registration and Optimization of Household Registration System}

A registered residence system is a basic state administrative system. This system is inherited from the household registration system which is directly related to land in Chinese history and is managed by family and clan as the unit. As early as the Northern Song Dynasty, in the vast rural areas, the development of cultivated land, the application of new technology, and the reform of agricultural tax led to the increase of productivity, the commercialization of agriculture, and the vigorous development of the land market. With the decrease of rural labor demand, many farmers lost their land, and some of them were forced to flow into urban industrial and commercial service industries, which promoted the formation and expansion of new urban small businessmen and wage earners. At the same time, this development has changed the tradition that urban industry and commerce rely mainly on bureaucrats and governments as the biggest market in the past. The industry and business of the new cities in the Northern Song Dynasty were manufacturing and selling mass consumer goods. It led to the expansion and popularization of industry and commerce. The development of a new urban economy and a new market has provided new impetus for urbanization and attracted the influx of all kinds of population. Therefore, the Northern Song Dynasty located the residents in the city of residence in the household registration system, and they paid the property tax and low-grade water to the government, and then took the labor service. It is enough to see the importance of household registration for a country, especially in a populous country like China. Its household registration and Hukou registration system are sufficient to change its pace of operation and economic development.

The modern household system is a legal system. The state collects, verifies, and confirms basic family information following the law. It plays an indispensable role in human identity, demography, and social management. The reform of the household registration system is inevitable in the city's urbanization process. This is to seek social reform and a breakthrough in social security, employment, and medical care. The reform of the household system has brought talents and skills to the region. It also has the possibility and inevitability to activate the local economy. It has promoted opportunities for migrant workers to start their businesses and find jobs. And it also solved the livelihood needs of migrant workers. Taking Guangzhou and Shanghai as the pilot, when the score of "migrant workers" reaches 60, there is the possibility of applying for registered permanent residence in Guangdong Province ${ }^{28}$. (Guangdong Provincial Government [GPG], 2010). It tells us that the reform of the household registration system is eliminating the great differences between urban and rural areas as far as possible. The form of urban and rural household registration makes the household registration with independent rights and interests have a unified state to realize equal citizenship status and rights. China's registered residence system reform is the focus of many years' work. The ultimate aim is to dilute the concept of household. This task is arduous and it has a very important impact on further promoting China's city development. It needs a good overall planning and top-down design to carry out a clear and systematic household registration reform. By that, it is possible to have the basic benefits of reform to solve the difficulties of urbanization ${ }^{29}$. (General Office of the State Council PRC [GOSC], 2014).

"By the end of 2020, a unified, people-oriented and efficient household registration system will be established in urban

\footnotetext{
${ }^{28}$ Guangdong Provincial Government. (2010). Guiding opinions on carrying out the work of migrant workers' point system in urban areas (Trial Implementation).

${ }^{29}$ General Office of the State Council PRC. (2014). Opinions on Further Promoting the Reform of the Household Registration System. People's Publishing House.
} 
and rural areas," the Ministry of Civil Affairs announced ${ }^{30}$. (GOSC, 2014). Under this new situation, the legitimate and stable work and residence in the permanent residence registered residence will become the basic condition for the relocation of household registration. That is to say, the residence will become an ultimate goal of the urban and rural household registration system holding the reform of registration system, which is another inevitable connection between city and space management. That is city registered residence management is the necessary condition for city space management, and the transfer of registered residence is also the foundation of urban household management. The inevitable connection between the two represents a development trend in the future. Therefore, to break the endless cycle, China's government's residence permit management measures need to be coordinated as with the registered residence registration reform. This management method was put forward at the Fifth Session of the Eleventh National Committee of the Chinese People's Political Consultative Conference in 2012. It aims to coordinate urban and rural social development and promote the integration of migrant workers. The government will improve the residence permit system: gradually abolish the restrictions on the application of residence permits, including the cancellation of qualifications, professional titles, criminal records, and other preconditions; at the same time, all local governments are required to give residence permits without any restrictions to permanent residents with non-local Hukou; the right to vote, the right to employment, the right to compulsory education, the right to skill training, the right to temporary assistance and the right to basic medical insurance. In terms of endowment insurance and unemployment insurance, residents with a residence permit and registered permanent residence shall be treated equally. The long-standing inequality can be solved through the fact that everyone can obtain basic social welfare without the management method of household registration or resident certificate limit. Only the elimination of such inequality can further promote the stability of local business conditions and income sources. Thus, we can establish a relatively good local urban and rural construction, to reduce the huge pressure brought by the existing population density of big cities. Of course, there is an inevitable coexistence relationship between residence permits and household registration for a certain period. In an ideal state, the urban residence permit should be banned, and then the benefits of population settlement can be unified. To sum up, under the current system and population foundation, registered residence reform should still be double grasps. The registered residence policy should be adjusted in the short term. In the long run, implementing a real household registration system reform should be completed. As for the future, its goal should be to implement the household registration management system well in 2025, then improve the unified system and mechanism between urban and rural areas, and ensure the equalization of basic public services. This kind of management can only promote the development of the urban economy and market economy ${ }^{31}$. (GOSC, 2014).

\section{Discussion}

The size of China in the Song Dynasty was as large as that in the Tang Dynasty. It is the richest, most famous, and most urbanized country in the world. After the melee from the end of the Tang Dynasty to the Five dynasties and ten kingdoms, the Northern Song period appeared as the Chinese Renaissance period. This amounts to a historic new world for China. It produced matching policies under enlightened governance of new social leadership and new values. It has produced excellent strategies in state management, economic policy, and the introduction of exotic crops. Great changes have also been developed in rural and urban areas. Then, China had a monetary economy. At the same time, foreign urban civilizations were concentrated in the Arab and Eastern Roman Empires. Religion and race are the criteria by which cities are built. However, the war led to the decline of all these countries in the 10th and 11th centuries. China is now in the early stages of preparing to return to its heyday. After the 70th anniversary of the founding of the People's Republic of China (after 2019), China has become one of the world's largest economies with the greatest potential for development through a series of large-scale construction projects in a planned way. On the whole, the people's life has risen to a well-off level. According to the data from the National Bureau of Statistics (2020), China's GDP reached 722278.6 trillion yuan in the first three quarters ${ }^{32}$. Although great progress has been made in China's economic development after the reform and opening-up, China's urbanization has brought some lagging factors to the process of industrialization, marketization, and nationalization. Among them exist labor productivity and the employment problem of industrial structure. There is also the weakness of the public economy and enterprise economy. The burden of COVID-19 has been added since 2020, and the new urbanization requires the continuous construction of the urban economy. It has to innovate and improve. Starting with the developed city clusters (4.1) and connecting with the

\footnotetext{
${ }^{30}$ General Office of the State Council PRC. (2014). Opinions of the State Council on Further Promoting the Reform of the Household Registration System.

${ }^{31}$ General Office of the State Council PRC. (2014). Opinions on Further Promoting the Reform of the Household Registration System. People's Publishing House.

${ }^{32}$ National Bureau of Statistics. (2020). Statistical Communique of the People's Republic of China on National Economic and Social Development 2020.
} 
developed economic environment in the Northern Song Dynasty (4.2), it seeks for the economic breakthrough in China's urbanization (4.3).

\subsection{Urban Agglomerations in China Today}

In the 1980s, Lu Dadao ${ }^{33}$ (2018), an academician of the Chinese Academy of Sciences and a famous economic geographer, put forward the Yangtze River economic belt, that is, the T-shaped development strategy, which is an economic belt under the overall spatial pattern formed by the coastal area as the strategic axis and the Yangtze River as the main axis $^{34}$. (Lu, 2018). The formation of this economic belt has led to the formation of the coastal economic belt and Yangtze River economic belt. This promotes the close connection of the Yangtze River urban agglomeration, and there is a "living community." It is a strategic plan for the economic development of the Yangtze River. It has also formed the urban agglomeration along the road, railway, and other transportation hubs.

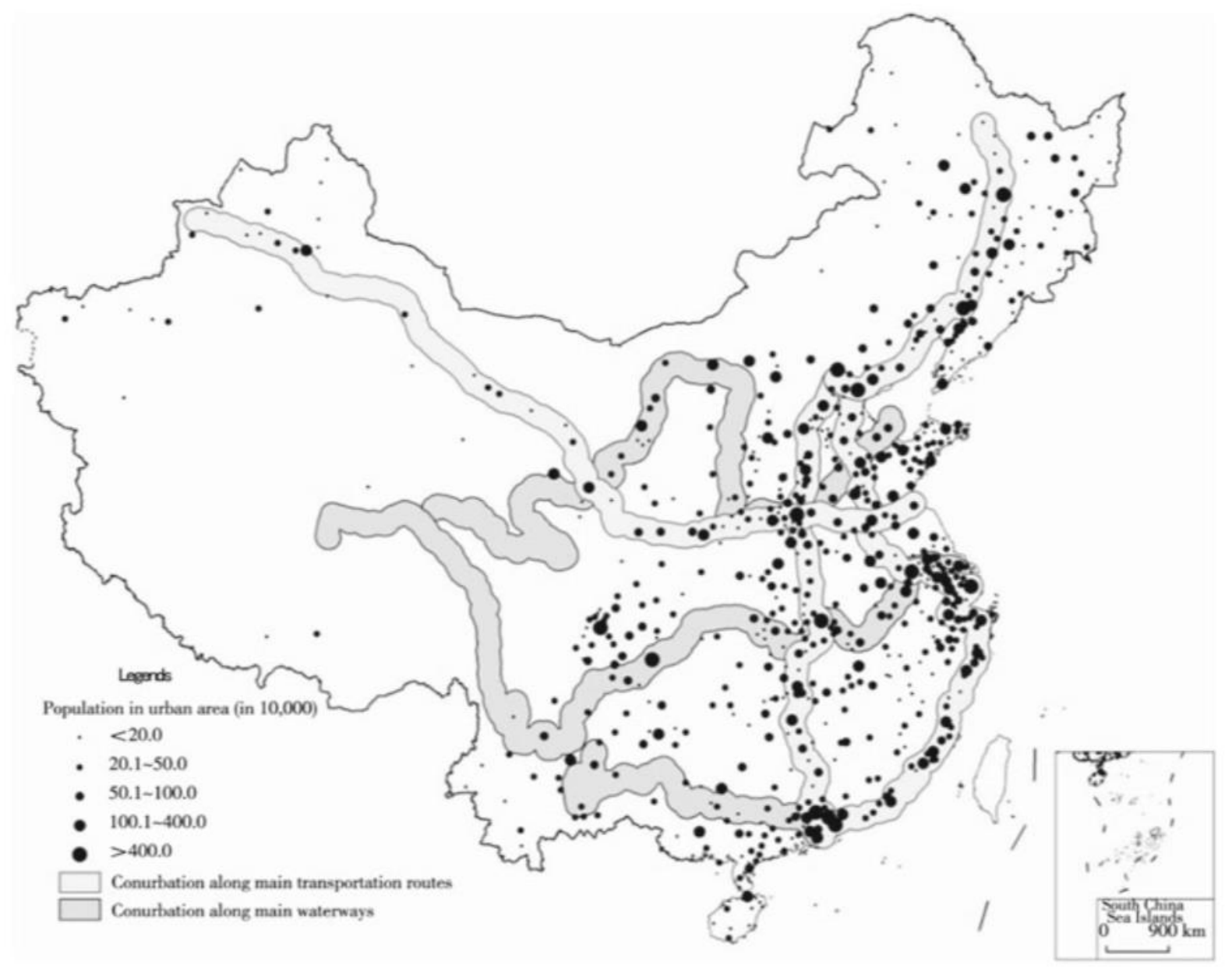

Figure 3. Co-urbanization Along the Urban Agglomerations in China

Source: China Urban-Rural Construction Statistical Yearbook (2011)

\footnotetext{
33 Institute of Geography, CAS, Beijing, China

${ }^{34}$ Lu, Dadao. (2018). The Great Protection of the Yangtze River and the Sustainable Development of the Yangtze River Economic Zone: to Realize the Sustainable development of the Yangtze River Economic Belt.
} 
Table 3. Overview of Urban Agglomerations in China, $2011^{35}$

\begin{tabular}{|c|c|c|c|c|c|}
\hline Urban agglomeration & $\begin{array}{l}\text { Areas } \\
\left(\mathrm{km}^{\wedge} 2\right)\end{array}$ & $\begin{array}{l}\text { City } \\
\text { Number }\end{array}$ & $\begin{array}{l}\text { Urban Population } \\
\text { million people) }\end{array}$ & $\begin{array}{l}\text { (inCity density (in cities/ } \\
\qquad 1000 \mathrm{~km}^{\wedge} 2 \text { ) }\end{array}$ & $\begin{array}{l}\text { /Urban population density (in } \\
\text { people/ } \mathrm{km}^{\wedge} 2 \text { ) }\end{array}$ \\
\hline Yangtze River & 479252 & 60 & 47.850 & 0.125 & 100 \\
\hline Pearl River & 183733 & 23 & 27.471 & 0.125 & 150 \\
\hline Yellow River & 435714 & 44 & 27.684 & 0.101 & 64 \\
\hline Beijing-Guangzhou Line & 228607 & 68 & 75.777 & 0.297 & 331 \\
\hline Beijing- Harbin Line & 168570 & 32 & 48.148 & 0.190 & 286 \\
\hline Beijing-Shanghai-Shenzhen Line & 314664 & 98 & 140.065 & 0.311 & 445 \\
\hline Lianyungang-Lanzhou-Urumqi & 397697 & 48 & 31.292 & 0.121 & 79 \\
\hline Line & & & & & \\
\hline
\end{tabular}

According to Figure 3 and Table 3, the buffer zone superposition analysis method is studied and analyzed for urban agglomerations. Structurally, the length of the buffer is $50 \mathrm{~km}$. Urban Agglomerations in the Yangtze River, Yellow River, and Zhuhai are the main spatial distribution of urban agglomerations in China. The total land area of these three urban agglomerations accounts for $11.44 \%$ of China's land area. The total population of urban agglomeration accounts for $19.33 \%$ of China's urban population ${ }^{36}$. (Wei, 2019). The population density of these three urban agglomerations is about twice that of the average-in China.

Due to the adoption of the T-type development strategy, the urban agglomeration of the Yangtze River artery is the largest. There are 60 cities with a total population of more than 47 million. In terms of important roads and railways, Beijing Guangzhou, Beijing Harbin, Beijing Shenzhen, Lianyungang, and Lanzhou Urumqi are the main urban agglomerations. These four urban agglomerations account for 10.97\% of the land area in China. The number of cities in the four major urban agglomerations accounts for $34.86 \%$ of the total number of cities in China. The total population of these four urban agglomerations accounts for $55.71 \%$ of China's urban population ${ }^{37}$. (Wei, 2019). However, due to the connection between cities along the line, the population density of urban agglomerations has reached about 4 or 5 times the average urban population density in China. Regardless of Chengdu, Taiyuan, Dalian, Qingdao, Hefei, and Nanning, there are 29 big cities with a population of more than 2 million in the same area. High-quality transportation infrastructure not only strengthens the intercity connection, but also promotes the economic development of cities along the line. With the construction of a rapid transportation network, especially the construction of a "four vertical and four latitudes" high-speed railway network, China will continue to build an urban agglomeration network.

At present, an urban agglomeration is being further constructed in the form of a network. The concept of "spatial field energy" is used to describe Chinese cities, population, and economy. The spatial field energy is the abstract expression of the ability to search, which is produced by the regional connection channel to drive the development of the peripheral areas. It is also an effective means to reflect the regional economic development pattern and spatial differences. Thus, from the regional point of view, the areas with high spatial field energy are greatly affected by the central city. The region will also be more closely linked, with relatively large growth potential. On the other hand, the regional fluctuation effect is small when the spatial field energy is low or far away from the central city. As shown in Figure 2, the Yangtze River Delta, the Pearl River Delta, and the Beijing Tianjin Hebei region are closely linked urban agglomerations. They are relatively mature. The urban agglomerations in central and southern Liaoning, Shandong Peninsula, and Changsha-Zhuzhou-Xiangtan City Group areas are also growing. With the development of modern transportation networks, some urban agglomerations have been connected. The Yangtze River Delta, the middle reaches of the Yangtze River, and Chengdu Chongqing urban agglomeration has formed new urban agglomerations with Hefei as the center and along important rivers. Along the railway line from Lianyungang to Lanzhou and Urumqi, urban agglomerations of Henan Province, Guanzhong to Tianshui (Guantian Economic Zone), Lanzhou to Xining, and the North slope of Tianshan Mountains are formed.

35 China Urban Construction Statistical Yearbook. (2011).

${ }^{36}$ Wei, Houkai. (2019). Strategic Thinking About Urbanization in China: The Path to Harmony and Prosperity. Urbanization in China. Chapter 1,103-105.

${ }^{37}$ Wei, Houkai. (2019). Strategic Thinking About Urbanization in China: The Path to Harmony and Prosperity. Urbanization in China. Chapter 1, 105. 


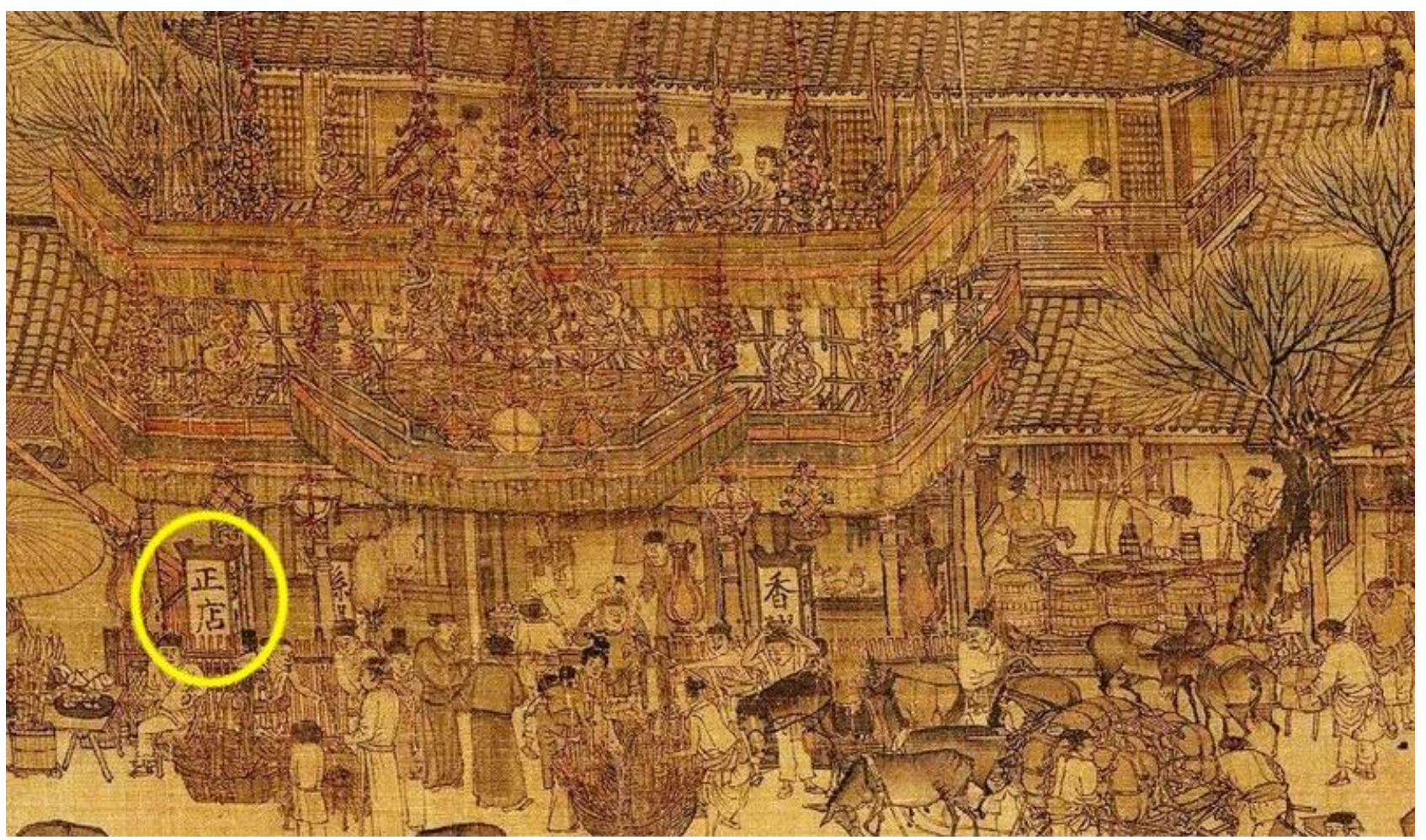

Figure 4. Shops (places for people to stay) on the Qingming Scroll

Source: Qingming Scroll (Anonymous, 2020).

In the Report on the Integration of China's Urban Agglomerations, the integration level of 12 large urban agglomerations in China has been evaluated. (China Development Research Foundation [CDRF], 2019). The 12 urban agglomerations cover 157 cities in total. The 12 urban agglomerations selected in the report are Beijing Tianjin Hebei, Yangtze River Delta, Pearl River Delta, Chengdu Chongqing region, Wuhan Central Area, Changsha Zhuzhou Xiangtan area, South Central Liaoning, Harbin Changcheng City Group, Guanzhong Plain, Central Plains, Haixi Mongolian and Tibetan Autonomous Prefecture and the Shandong Peninsula. The analysis shows that from 2006 to 2015, the GDP of the 12 urban agglomerations increased from $70.56 \%$ to $82 \%^{38}$. (CDRF, 2019). Among them, the economic share of the Yangtze River Delta, Beijing Tianjin Hebei, and Pearl River Delta exceed 40\%. The important driving forces of the integrated development of urban groups and regional average balanced development are increasing.

Therefore, as long as we do a few good economic activities in urban agglomerations, China's economy can have good developments. From the international experience, we can find that the process of human beings, that is, the process of talents, is enough to promote the development of the economy and innovation. The investment benefit of urban agglomeration is the highest. However, urban agglomeration cannot solve all the urban economic problems, many of which rely on the development of urban agglomerations still have great room for progress. There is also a need to strengthen and improve integration and regional connectivity for promoting the development of the remaining urban agglomerations and surrounding towns.

\subsection{Urban Agglomeration Economy in the Song Dynasty on the Qingming Scroll}

China's economic development has entered a new normal, and the economic speed will gradually change from a high-speed economy to a medium high-speed economy. The continuous optimization of economic structure and the innovation drive will become a new feature of China's economy. At the same time, according to experience, urbanization is the main driving force to maintain the rapid economic growth and the development of a well-off society in an all-around way. And it is also an important way to realize the great Chinese dream. Under such a basic concept, what we can do is to improve the existing situation. Among them, the new trend of urban economic space is the breakthrough of urban economic development. At present, there are many demands for the development of urbanization transformation, among which the urbanization development trend of speed type to quality type is imperative. To solve

${ }^{38}$ China Development Research Foundation. (2019). Report on the integration of China's Urban Agglomerations. 
the goal of continuous development of urban economic integration which we emphasized in this part, we think it is necessary to study the urban economy of the Northern Song Dynasty. Because the Northern Song Dynasty represented a major historical period of China's global economic prosperity. Under such a state of underdevelopment in all aspects, prosperity was difficult to write, but China did during the Song Dynasty. To continuously optimize and break through the development, "Life reform" has become a means of urban planning, and listening to various opinions to distinguish right from wrong is a necessary criterion in urban planning.

"Qingming Scroll" records life in Kaifeng, the capital of the Northern Song Dynasty, and confirms the special economic situation of China in this era. In the history of the Song Dynasty, it is estimated that industry, commerce, and agriculture account for half of the economy of the Northern Song Dynasty. In 1077, the annual total account was 70.7 million. According to the current GDP form, the GDP in the Song Dynasty in 1000 was estimated as 26.55 billion US dollars, accounting for $22.7 \%$ of the global GDP, and the per capita GDP reached 2280 US dollars, while the per capita GDP of Britain only reached 1250 US dollars in 1800 after the industrial revolution ${ }^{39}$. (Xue, 2017). So, what was the reason why the Northern Song Dynasty reached such a prosperous stage in 1000 years? The answer lies in the city business activities and the development of the urban economy in the Northern Song Dynasty.

According to Figure 4, "Sunyang Zhengdian"40 in the picture of the Qingming Scroll is a licensed pub. And counted the liquor sellers in Bianjing of Northern Song Dynasty in the "Qingming Scroll," there are 72 such licensed liquor merchants in Bianjing. In addition, there are many wine shops called "foot shops," and there is one named "ten thousand feet shop" in the picture, and there are two related direct selling shops with the temperament of green and white cloth. In the early Northern Song Dynasty, the wine tax reached 1.85 million yuan, which was about $10 \%$ of China's currency tax at that time. The total tax revenue in 1070 million yuan is about $18 \%$ of the total tax revenue, that is to say, the total tax revenue is about $18 \%$ in the period of the Qing Dynasty. In addition to the wine industry everywhere, there are countless restaurants and teahouses. Most of these snack shops and restaurants or steamed bread takeout industries are street vendors, which are also the most popular consumption environment. Most of these environments are teahouses and restaurants frequented by the lower classes related to water transport. In the picture, we can see that people on the street are holding a bowl of wonton or noodles, where they will leave after eating. Of course, there are many commercial streets in Bianjing. In addition to six commercial streets, such as Yu street and Bianhe street, there are also markets classified according to commodities, including a series of commercial and professional markets, such as fabric street, grocery store, and Zhenxiang Shop ${ }^{41}$. As far as the explanation is concerned, there will be many people who do not have their own shops and just put a shop name of their own on the street. Then the shopkeeper stood beside him with a load on his shoulder or a load on the ground.

It is in such a prosperous environment, urban planning and economic space are in an open state, the free competition in the market will continue to develop in a benign direction. In addition to the simple conventional commerce, the Song Dynasty also retained the morning and evening markets ${ }^{42}$, as well as the rural markets in the suburbs. Most of these areas are made up of temporary transactions. (Meng, 1982). According to the records of "Dongjing Menghua Lu"43, most of the fruits and vegetables on the market are very fresh, and the market is also the most prosperous. (Meng, 1982). This way of free selling enables farmers, craftsmen, and so on to obtain the freedom of commerce and trade. But similarly, to ensure the government's management of the city, the city's excellent free trade also needs commodity control. In Song Dynasty, there is a tax standard for 27 kinds of four kinds of commodities, and the commercial people are also charged according to the two tax methods of residence tax and national tax. Among them, residence tax is a transaction tax, and tax is a circulation tax, which is $3 \%$ and $2 \%$ respectively. For individual vendors, such a policy is beneficial to the people and promotes business development.

\subsection{The Breakthrough in Urban Economic Development: Street-Stall Economy}

Future urban space development needs to optimize the space stock. In such a state of development, its development

39 Xue, Fengxuan. (2017). Qingming Scroll: memories of prosperity in the Northern Song Dynasty. Knowledge of literature and history (08), 49.

40 "Zhengdian" refers to the liquor wholesale stores.

41 "Zhenxiang shop" refers to spice shop.

${ }^{42}$ Meng, Yuanlao. (1982). Deng Zhicheng's Annotation of Dongjing Menghua Lu (Vol 3). Trading of 10 thousands of citizens in Xiangguo Temple is opened five times a month, 93. "Meiyue Shuowang, Sanba Ri Jikai......" means: It will be opened on the 3 rd and 8 th of every month......

${ }^{43}$ Meng, Yuanlao. (1982). Deng Zhicheng's Annotation of Dongjing Menghua Lu (Vol 3). "Baili Zhinei, Bingwu Xiandi." means: Within a hundred $\mathrm{Li}$, there is no idle space. 
mode will change from extensive thinking to intensive thinking since the reform and opening up. This, in turn, will improve the quality of existing urbanization. The Central Work Conference on Urbanization ${ }^{44}$ (2013) and the National New Urbanization Rules (2014) both proposed to control the "ceiling" of construction land. This also delimits the requirement of urban convenience and urban ecology red line. To ensure the better development of China's urbanization and the spread of land use benefits, urban industrial structure and economic development will face a breakthrough.

In most of the current urban reports in China, the construction of smart cities conforming to the development of modern science and technology and informatization has become a necessary means to coordinate all aspects of urban development resources and promote innovative technology. But can the emergence and rapid development of smart space provide maximum convenience for future urban space? Are our Cloud technology, big data, and artificial intelligence the only mission of urbanization? Will the innovation technology revolution brought by automation technology all over the urban space promote the economic development of a large population country? Is it bringing about less pressure on infrastructure, order, and security? This concept comes from the report on emerging technology trends 2016-2045 published by the United States. For China, which is still in practice to ensure the equal rights and interests of urban and rural citizens, and is still committed to transforming rural society into urban society, it is too early to talk about this issue. After several decades of vigorous implementation, it may be better for the development of China's effective smart city. It is better to choose the mode left by our ancestors to maintain economic balance and create a new domestic economy: street-stall economy and small shop economy ${ }^{45}$. (XNA, 2020).

In the previous paper, we have made a detailed review of the free trade market in the Northern Song Dynasty, and believe that this form of trade can be used for reference. In the same way, we need to neutralize existing urbanization or related national policies. After the epidemic in 2020, the idea of street-stall economy and small shop economy advocated by the central civilization office is in line with our needs, and we believe that we should continue to support and carry forward. In Chinese, the word "Chengshi" (city) has different meanings. The word "Cheng" represents defense function, while "Shi" represents market and trade. In particular, the latter shows the characteristics of agglomeration and communication, which can meet the demand of the intensive market. As the root of the city, the source of the market is the ground stall and small shop, which is also the lowest market. It can be said that it is the most basic way to transform the urban-rural differences that may not be perfect in urbanization into excessive integration. At present, China is in the transition stage from farmers to citizens. What the street-stall economy can do is to turn the income gap of citizens into a usable resource, and then solve the problem of income increase and expenditure of low-income groups. At the same time, in the face of the major disaster of urbanization in a district, the new coronavirus epidemic situation, maintaining the existing urbanization state, reducing the internet load has become a great benefit of the street-stall economy.

\section{Acknowledgment}

To thank Alejandro Abbud Torres Torija, the initial advisor of my thesis. And to thank the people who have inspired me on this topic, my university Sciences Po de Paris, and my parents as the ones granting financial supports for my study.

\section{References}

China Development Gateway. Hu: GDP grew at an average annual rate of 9.8 percent from 1978 to 2007. Retrieved from http://www.chinagate.com.cn

China Development Research Foundation. (2010). China development report: China's new urbanization strategy for human development. Beijing: The People's Press.

China Development Research Foundation. (2013). China's New Urbanization Strategy. Washington, DC: Abingdon, OX: Routledge. https://doi.org/10.4324/9780203074930

China Development Research Foundation. (2019). Report on the integration of China's Urban Agglomerations. Retrieved from https://cdrf.org.cn/jjh/pdf/yitihua.pdf

General Office of the State Council PRC. (2014). Opinions of the State Council on Further Promoting the Reform of the Household Registration System. Beijing: Guofa, No.25. Retrieved from http://www.gov.cn/zhengce/content/2014-07/30/content_8944.htm

General Office of the State Council PRC. (2014). Opinions on Further Promoting the Reform of the Household Registration System. Beijing: People's Publishing House.

Gernet, J. (1985). A History of Chinese Civilization. Cambridge: Cambridge University Press.

${ }^{44}$ Ling, Chen and Zhao, Gang. (2013). A Central Work Conference on Urbanization Has Been Held in Beijing.

45 On May 28, 2020, Prime Minister Li Keqiang attended a Press Conference. 
Jian, X. H., \& Huang, K. (2010). Empirical Analysis and Prospect Forecast of China's Urbanization Level and Speed. Economic Research Journal, 3, 30-41.

Jiang, Q. X. et.al. (1981). The Urban Economy of Bianjing in the Northern Song Dynasty Viewed from the Qingming Scroll and Dongjing Menghua Lu. Chinese Social Sciences, 4, 185-207.

$\mathrm{Li}, \quad$ K. Q. (2019). Report on the Work of the Government of the State Council. Retrieved from http://www.gov.cn/zhuanti/2019qglh/2019lhzfgzbg/

Li, K. Q. (2020). Report on the Work of the Government of the State Council. Retrieved from http://www.gov.cn/zhuanti/2020qglh/2020zfgzbgdzs/2020zfgzbgdzs.html

Ling, C., \& Zhao, G. (2013). A Central Work Conference on Urbanization Has Been Held in Beijing. Beijing: CCTV. Retrieved from http://politics.people.com.cn/n/2013/1214/c1024-23841512.html

Lu, D. D. (2018). The great protection of the Yangtze River and the sustainable development of the Yangtze River Economic Belt: Understanding and Suggestions on the Important Instructions of the President for Internship to Realize the Sustainable Development of the Yangtze River Economic Belt. Journal of Geography, 073(010), 1829-1836.

Meng, Y. L. (1982). Deng Zhicheng's Annotation of Dongjing Menghua Lu. Beijing: Zhong Hua Book Company.

Ministry of foreign affairs of the People's Republic of China. (2002). Full text of Jiang Zemin's Report at 16th Party Congress on Nov. 8, 2002. Beijing: 16th CPC National Congress. Retrieved from https://www.fmprc.gov.cn/mfa_eng/topics_665678/3698_665962/t18872.shtml

Ministry of Housing and Urban-Rural Development of the People's Republic of China. (2011). China Urban Construction Statistical Yearbook. Beijing: China Planning Publishing House. Retrieved from http://www.mohurd.gov.cn/xytj/tjzljsxytjgb/jstjnj/

Ministry of Housing and Urban-Rural Development of the People's Republic of China. (2015). China Urban Construction Statistical Yearbook. Beijing: China Planning Publishing House. Retrieved from http://www.mohurd.gov.cn/xytj/tjzljsxytjgb/jstjnj/

Morris, A. E. J. (1994). History of Urban Form. Essex: Longman.

National Development and Reform Commission. (2016). National New Urbanization Rules (2014-2020). Beijing: Development Strategy and Planning Division.

Shenzhen Daily. Xi declares 'complete victory' in war on poverty. 2021. Retrieved from fhttp://http://www.sz.gov.cn/en_szgov/news/photos/content/post_8570805.html

Shi, H. N. (2012). Urbanization's Effect on Human Capital Accumulation in China. Beijing: China Soft Science, 3, 117-127.

Song, Li. (2011). On the Management of Bianjing Commercial Market in Northern Song Dynasty. Journal of Kaifeng University, 5(3).

Survey Center of National Bureau of Statistics. (2013). China Population and Employment Statistics Yearbook. Beijing: Division of Population and Employment Statistics, National Bureau of Statistics of China. Retrieved from http://www.stats.gov.cn/tjsj/tjcbw/201505/t20150526_1076519.html

The General Report Authoring Team. (2012). Annual Report on Urban Development of China (Vol. 5). Beijing: Social Sciences Academic Press (China).

Wei, H. K. (2019). Strategic Thinking About Urbanization in China: The Path to Harmony and Prosperity. Urbanization in China. https://doi.org/10.1007/978-981-13-1408-7_3

Wen, R. J. (1993). Translation and annotation of Kao Gong Ji. Shanghai: Ancient Books Publishing House.

Wu, T. (1982). The Construction and Layout of Bianjing in the Northern Song Dynasty (Vol 3).

Wu, Z. Q. (2008). The Practical Significance of the New Urbanization Road. Beijing: Journal of the Party School of the CPC Central Committee, 12(004), 95-97.

Xinhua News Agency. (2013). Xi Jinping and Li Keqiang made important speeches at the Central Economic Work Conference. Beijing: Central Government Portal. Retrieved from http://www.gov.cn/ldhd/2013-12/13/content_2547546.htm

Xinhua News Agency. (2020). Chinese Premier Li Keqiang Answers Questions from Chinese and Foreign Journalists. Beijing: Xinhua Publishing House. Retrieved from 
https://baijiahao.baidu.com/s?id=1667933645787238007\&wfr=spider\&for=pc

Xinhua News Agency. (2020). Report on the Work of the Government for 2020. Beijing: Xinhua Publishing House. Retrieved from https://baijiahao.baidu.com/s?id=1668095110513176593\&wfr=spider\&for=pc

Xue, F. X. (2017). Qingming Scroll: memories of prosperity in the Northern Song Dynasty. Knowledge of Literature and History (08).

Zheng, Z. D. (1958). Study on the Qingming Scroll. Beijing: Cultural Relics Publishing House.

Zhou, B. Z., \& Chen, Z. (2007). The History of China: Song History. Chapter 3 "urban and rural divide and rule and the emergence of new registered residence system in urban and rural areas." Shanghai: People's Publishing House.

Webpage:

http://www.dongfangshoucang.com/article.php?id=216

https://mr.baidu.com/r/q8psyemi5i?f=cp\&u=371864ce30cf63a8

\section{Copyrights}

Copyright for this article is retained by the author(s), with first publication rights granted to the journal.

This is an open-access article distributed under the terms and conditions of the Creative Commons Attribution license which permits unrestricted use, distribution, and reproduction in any medium, provided the original work is properly cited. 